\title{
Growth of $\beta-\mathrm{Ga}_{2} \mathrm{O}_{3}$ single crystals using vertical Bridgman method in ambient air
}

\author{
*K. Hoshikawa ${ }^{1}$, E. Ohba ${ }^{2}$, T. Kobayashi², J. Yanagisawa², C. Miyagawa², Y. Nakamura² \\ Faculty of Engineering, Shinshu University, Nagano, Japan ${ }^{1}$ \\ Fujikoshi Machinery Corp., Nagano, Japan² \\ *E-mail: khoshi1@shinshu-u.ac.jp
}

\begin{abstract}
A new approach to $\beta-\mathrm{Ga}_{2} \mathrm{O}_{3}$ single crystal growth was studied, using the vertical Bridgman (VB) method in ambient air, while measuring the $\beta-\mathrm{Ga}_{2} \mathrm{O}_{3}$ melting temperature and investigating the effects of crucible composition and shape. $\beta-\mathrm{Ga}_{2} \mathrm{O}_{3}$ single crystals $25 \mathrm{~mm}$ in diameter were grown in platinum-rhodium alloy crucibles in ambient air, with no adhesion of the crystals to the crucible wall. Single crystal growth without a crystal seed was realized by (100) faceted growth with a growth direction perpendicular to the (100) faceted plane.
\end{abstract}

A2 Bridgman technique, A2 Growth from melt, A2 Single crystal growth, B1 Oxides, B2 Semiconducting gallium compounds

\section{Introduction}

$\beta-\mathrm{Ga}_{2} \mathrm{O}_{3}$ is an oxide semiconductor with a large band gap of $4.7-4.9 \mathrm{eV}[1,2]$. It is expected to be useful in future power devices featuring high power, high breakdown voltage and high current density [3-5]. $\beta-\mathrm{Ga}_{2} \mathrm{O}_{3}$ single crystals can be grown from a melt [6-9], as can semiconductor silicon crystals and oxide crystals such as sapphire and $\mathrm{LiNbO}_{3}$. Thus it is likely that we will be able to produce large size crystals economically and in an energy-efficient manner, rather than bulk crystals of $\mathrm{SiC}$ and/or GaN.

$\beta-\mathrm{Ga}_{2} \mathrm{O}_{3}$ bulk crystals have until now been grown by optical floating-zone (OFZ) $[7,10,11]$, Czochralski (CZ) $[6,8,12]$ and edge-defined film-fed growth (EFG) $[9,13]$ methods. $\beta-\mathrm{Ga}_{2} \mathrm{O}_{3}$ crystals can generally be produced in ambient air by OFZ growth because the method requires no crucible. Crystals grown by the OFZ are dimensionally limited due to the limited size of the light spot. $\beta-\mathrm{Ga}_{2} \mathrm{O}_{3}$ crystals produced by the $\mathrm{CZ}$ and EFG methods have been grown from melts in iridium crucibles, and $\beta-\mathrm{Ga}_{2} \mathrm{O}_{3}$ substrates grown by the EFG method have recently become commercially available [9]. However, these two methods have some technical problems, such as the necessity of atmosphere control due to the use of an iridium crucible.

An oxidizing atmosphere is desirable for $\beta-\mathrm{Ga}_{2} \mathrm{O}_{3}$ crystal growth because $\beta-\mathrm{Ga}_{2} \mathrm{O}_{3}$ is an oxide 
material that undergoes reductive decomposition $\left(\mathrm{Ga}_{2} \mathrm{O}_{3} \rightarrow 2 \mathrm{Ga}+3 / 2 \mathrm{O}_{2}\right)$ at high temperature $[6,8,12,14,15]$. However, iridium crucibles are not useful in atmospheres with more than a few percent of oxygen partial pressure at the high temperature required to melt $\beta-\mathrm{Ga}_{2} \mathrm{O}_{3}$ because iridium will easily oxidize and evaporate under those conditions [12,16]. This presents an atmosphere control problem for $\beta-\mathrm{Ga}_{2} \mathrm{O}_{3}$ crystal growth in an iridium crucible. Furthermore, crystal pulling from the melt (OFZ, CZ, EFG) may complicate diameter control, especially in the case of thermally unstable compounds such as $\beta-\mathrm{Ga}_{2} \mathrm{O}_{3}$.

We are studying the growth of $\beta-\mathrm{Ga}_{2} \mathrm{O}_{3}$ single crystals by the VB $[17,18]$ method. Diameter control is unnecessary in the VB method because the diameter is determined by the inner diameter of the crucible. Additionally, growing $\beta-\mathrm{Ga}_{2} \mathrm{O}_{3}$ crystals in air might be a reasonable expectation because of the possibility of using crucibles made of a platinum-based alloy in a very low temperature gradient, so we have explored a new approach to $\beta-\mathrm{Ga}_{2} \mathrm{O}_{3}$ single-crystal growth in ambient air. In this paper we report our investigation, in which we measured the melting temperature of $\beta-\mathrm{Ga}_{2} \mathrm{O}_{3}$, designed a crucible of a suitable material and shape, grew $\beta-\mathrm{Ga}_{2} \mathrm{O}_{3}$ crystals by the $\mathrm{VB}$ method without seeding, and characterized the crystals grown.

\section{Experiment}

A schematic diagram of the VB growth furnace used in this experiment is shown in Fig. 1. A radio-frequency induction heating furnace was constructed, with a work coil, heat shields, a heater, a crucible, a thermocouple and a crucible shaft with a rotation and translation mechanism. The radio-frequency of the work coil was $15 \mathrm{kHz}$. The heat shields were constructed from zirconia and alumina ceramics. The heater was made of Pt-Rh (70-30\%) alloy with a melting temperature of more than $2173 \mathrm{~K}$. The crucible was made of a platinum-rhodium alloy, inner diameter $25 \mathrm{~mm}$, and $50 \mathrm{~mm}$ long. Fig. 2 shows diagrams of the temperature distribution in the furnace (Fig. 2(a)) and the growth processes (Fig. 2(b)). In the preparation process, a sintered body of $\beta-\mathrm{Ga}_{2} \mathrm{O}_{3}$ raw material was set in the crucible. In the growth process, the raw material was melted and VB growth was carried out by raising (Fig. 2(b-1)) and lowering (Fig. 2(b-2)) the crucible through the temperature regions shown in Fig. 2(a) at a suitable rate, typically $0.5 \mathrm{~mm} / \mathrm{h}$ with a rotation of $3 \mathrm{rpm}$. It was very important to measure the temperature precisely because we could not observe the melting and growth processes inside the crucible. For the temperature measurement, we used a B-type thermocouple that could measure temperatures up to $2093 \mathrm{~K}$ in air.

The crystals grown were cut and both sides mirror-polished as experimental specimens with a (100) plane about $0.5 \mathrm{~mm}$ thick. A crossed polarizer was used to evaluate the low-angle grain boundaries (LAGBs). X-ray topography was also used to evaluate the LAGBs, the internal residual stress and the dislocation distribution. Impurity analysis was carried out by GDMS (Toray Research Center, Inc.). 


\section{Results and Discussion}

\subsection{Melting temperature of $\beta-\mathrm{Ga}_{2} \mathrm{O}_{3}$}

It was necessary to find the precise melting temperature of $\beta-\mathrm{Ga}_{2} \mathrm{O}_{3}$ for designing the material and the shape of the crucible to be used for the VB method. However, there have been many reports of widely differing $\beta-\mathrm{Ga}_{2} \mathrm{O}_{3}$ melting temperatures: $1998 \mathrm{~K}[9,19], 2013 \mathrm{~K}[19,20], 2067 \mathrm{~K}[15]$, $2068 \mathrm{~K}$ [21], $2080 \mathrm{~K}$ [22], and $2093 \mathrm{~K}$ [8,12]. Thus we had to determine the precise melting temperature of $\beta-\mathrm{Ga}_{2} \mathrm{O}_{3}$ in our furnace with an air atmosphere.

The method used to measure the melting temperature of $\beta-\mathrm{Ga}_{2} \mathrm{O}_{3}$ is shown in Fig. 3 . The $0.2 \mathrm{~mm}$ thick platinum-rhodium alloy container, charged with several grams of sintered $\beta-\mathrm{Ga}_{2} \mathrm{O}_{3}$, was set in the heating zone with a uniform temperature distribution in the furnace shown in Fig. 1. The heating power was slowly increased at a constant rate. The temperature change at the container bottom was measured, determined by a B-type thermocouple welded to the container bottom as shown in Fig. 3(a). A melting onset temperature of $2062 \mathrm{~K}$ and a melting completion temperature of $2066 \mathrm{~K}$ were observed, as shown in Fig. 3(b). The solidification of completely melted $\beta-\mathrm{Ga}_{2} \mathrm{O}_{3}$ was also observed during the heating power reduction stage, as shown in Fig. 3(b). It was confirmed that the sintered $\beta-\mathrm{Ga}_{2} \mathrm{O}_{3}$ in the container shown in Fig. 3(c) was changed to the solidified $\beta-\mathrm{Ga}_{2} \mathrm{O}_{3}$ shown in Fig. 3(d). This experiment showed that the melting temperature of $\beta-\mathrm{Ga}_{2} \mathrm{O}_{3}$ was about $2066 \mathrm{~K}$ in ambient air.

The crucible material in the VB growth furnace must have and hold a melting temperature more than $50 \mathrm{~K}$ higher than the $\beta-\mathrm{Ga}_{2} \mathrm{O}_{3}$ melting temperature. We could design and construct the crucibles with a platinum-based, 10-to-20 percent rhodium alloy for the task of $\beta-\mathrm{Ga}_{2} \mathrm{O}_{3}$ crystal growth by the VB method in ambient air.

\subsection{Growth of $\beta-\mathrm{Ga}_{2} \mathrm{O}_{3}$ single crystals by the $\mathrm{VB}$ method}

Single crystals grown by the VB method without seeding in a full-diameter crucible, and in a conical crucible with a thin seed well, are shown in Fig. 4. The $\beta-\mathrm{Ga}_{2} \mathrm{O}_{3}$ crystal $25 \mathrm{~mm}$ in diameter and $25 \mathrm{~mm}$ long shown in Fig. 4(a) was grown in the full-diameter crucible shown in Fig. 4(a') and the $\beta-\mathrm{Ga}_{2} \mathrm{O}_{3}$ crystal $25 \mathrm{~mm}$ in diameter and $20 \mathrm{~mm}$ long shown in Fig. 4(b) was grown in the conical crucible with a thin seed well shown in Fig. 4(b’). We could easily release the crystals grown in the crucibles by destructively peeling them from the crystals (stripping), and we observed that the crystal surfaces were very smooth and shiny. It is known that in the VB method, releasing the crystal without serious damage to it is very difficult due to its adhesion to the crucible. In the present instance, we found that $\beta-\mathrm{Ga}_{2} \mathrm{O}_{3}$ crystals did not adhere to our platinum-rhodium alloy crucibles with either vertical or conical walls. We conclude that single crystals of $\beta-\mathrm{Ga}_{2} \mathrm{O}_{3}$ can be grown not only in full-diameter crucibles but also in conical crucibles.

Three representative crystals grown by the VB method without seeds are shown in Fig. 5. Crystal 
A (Fig. 5(a)) is a polycrystalline ingot, and crystal B (Fig. 5(b)) is a crystal ingot that was initially grown as a polycrystal and that abruptly changed to a single crystal, and crystal C (Fig. 5(c)) is a crystal ingot grown as a single crystal from the starting edge to the terminal edge of the ingot. It is well known that in the process of single crystallization by the VB method without a seed, a multicrystal with many growth directions nucleates at the starting edge, and the multiple growth directions gradually decrease in number due to growth rate anisotropy, finally yielding a single crystal. In our $\beta-\mathrm{Ga}_{2} \mathrm{O}_{3}$ growth, however, a very different process was observed, as the multicrystal changed abruptly to a single crystal as shown in crystal B, or a single crystal was grown from the starting edge, as initiated by a single crystal seed, as shown in single crystal $\mathrm{C}$. We can conclude from this experiment that $\beta-\mathrm{Ga}_{2} \mathrm{O}_{3}$ single crystals are easily grown in a specific growth direction with very strong growth rate anisotropy. The specific direction will be discussed in the following section.

\subsection{Crystal growth habit and mechanism of $\beta-\mathrm{Ga}_{2} \mathrm{O}_{3}$}

The growth habit of a $\beta-\mathrm{Ga}_{2} \mathrm{O}_{3}$ single-crystal ingot spontaneously grown with a specific growth direction is shown in Fig. 6. The growth direction and some faceted planes observed on the ingots, grown without seeding, could be determined by observation and by X-ray analysis. We found that the top surface of the ingot was completely planar and mirror-like, and determined that it was a (100) plane. The specific growth direction, i.e. the direction from the bottom to the top of the ingot was in the direction perpendicular to the (100) plane. We considered from these findings that the (100) plane corresponded to the growth interface that resulted in faceted growth, as shown in a photograph (Fig. 6(a)) and in a schematic diagram (Fig. 6(b)). Other facets with (001) and (-100) planes were also observed at a side surface of the ingot as shown in Figs. 6(a) and 6(b). As is well known, the angle between (100) and (001) is approximately 104 degrees [23, 24], as shown by the axis notation in Fig. 6(c). We could also determine the [0-10] orientation perpendicular to both the [100] and the [001] orientations, as shown in Figs. 6(a) and 6(c). Fig. 7 shows photographs of a bottom view (Fig. 7(a)) and a side view (Fig. 7(b)) of an ingot that grew as a single crystal without seed. Note that a great number of needle-like crystals lined up in a [0-10] orientation were observed in a thin layer on the entire bottom plane as shown in the photograph of Fig. 7(a). However, we could observe that the needle like crystals suddenly changed to a single crystal within one millimeter growth from its starting edge at the crucible bottom as shown in Fig. 7(b). From the above observations, we can speculate that the reason why the $\beta-\mathrm{Ga}_{2} \mathrm{O}_{3}$ single crystals grew spontaneously in the direction perpendicular to the (100) plane with (100) faceted growth might be as follows. In the speculation, we consider that the temperature gradient in the growth direction near the growth interface was relatively large, likely larger than $10 \mathrm{~K} / \mathrm{cm}$, while the temperature gradient across the growth interface was small, likely smaller than $1 \mathrm{~K} / \mathrm{cm}$ during growth of the crystal shown in Fig. 7 (a) and (b). Such temperature gradients may occur in the VB growth system. At the first step, $\beta-\mathrm{Ga}_{2} \mathrm{O}_{3}$ micro-size crystals nucleated in the melt near the center of the crucible bottom where the melt was kept supercooled, and the micro-size crystals grew to needle-like crystals with [010] or [0-10] growth 
directions at the crucible bottom because of their easy growth orientations with higher growth rate despite the very small in-plane temperature gradient (less than $1 \mathrm{~K} / \mathrm{cm}$ ). Furthermore, many needle-like crystals that grew spontaneously fell into the same direction with relation to some partial temperature distribution and spread over the entire crucible bottom with the same growth orientations of [010] or [0-10] as shown in Fig. 7(a') At the next step, when the needle-like crystals on the crucible bottom grew upwards into the melt through the growth interface (with its large temperature gradient more than $10 \mathrm{~K} / \mathrm{cm}$ ) as the crucible was pulled downwards, the growth directions, initially having very different in-plane orientations, were forced to align to an orientation perpendicular to the (100) plane due to the lower growth rate in the direction perpendicular to the (100) plane as shown in Fig. 7(b'). Finally, the (100) faceted growth was retained due to the very low growth rate under the large temperature gradient in the growth direction and a uniform lateral temperature distribution in the growth interface plane. Relevant to the large growth rate anisotropy mentioned above, it was

reported by K. Sasaki et al. that the growth rate in the orientation perpendicular to (010) was highest, and about tenfold larger than the lowest rate in the direction perpendicular to the (100) plane in homo-epitaxial growth by ozone molecular beam epitaxy [25]. As for the large growth rate anisotropy between the orientations perpendicular to (010) and (100) planes, it is well known that the growth along the [010] is strongly favored because it is perpendicular to the normal directions of the strongest cleavage plane of $\beta-\mathrm{Ga}_{2} \mathrm{O}_{3}$ crystal, namely (100). Cleavage planes occur due to weak bonding, and are therefore well understood to show the lowest growth rates, which produces a strong facet plane. We conclude from our experimental results and these considerations that this faceted $\beta-\mathrm{Ga}_{2} \mathrm{O}_{3}$ single-crystal growth in the direction perpendicular to (100) plane in our unseeded VB method is due to the remarkable growth rate anisotropy between the very high growth rate in the direction perpendicular to (010) plane and the very low growth rate in the direction perpendicular to (100) plane.

\subsection{Characteristics of the $\beta-\mathrm{Ga}_{2} \mathrm{O}_{3}$ single crystals}

We introduce here tentative conclusions on the characteristics of the $\beta-\mathrm{Ga}_{2} \mathrm{O}_{3}$ single crystals grown by directional solidification without seed. Crossed polarizer observation and a transmitted x-ray topographic image of a (100) wafer are shown in Fig. 8. No LAGBs are observed with crossed polarizer [18] in Fig. 8(a), and the single-crystal whole-wafer (100) plane, with strong internal residual stress and high density of dislocations in the periphery, was also confirmed in the transmitted x-ray topography image as shown in Fig. 8(b). The results of impurity analysis are shown in Table 1 . The level of platinum and rhodium contamination that might originate from the crucible materials was as high as 3 to $30 \mathrm{wt}$. ppm in several ingots. Reducing these impurities may be a future requirement to control the crystals' semiconductor characteristics.

\section{Summary and Conclusions}


We investigated the melting temperature of $\beta-\mathrm{Ga}_{2} \mathrm{O}_{3}$, the crucible material and shape, the single-crystal growth of $\beta-\mathrm{Ga}_{2} \mathrm{O}_{3}$ by the $\mathrm{VB}$ method in ambient air, and the characterization of the crystals grown. The results are summarized as follows:

(1) The melting temperature of $\beta-\mathrm{Ga}_{2} \mathrm{O}_{3}$ was about $1793{ }^{\circ} \mathrm{C}$ and platinum-based 10 to 20 percent rhodium alloys were useful as crucible materials for melting $\beta-\mathrm{Ga}_{2} \mathrm{O}_{3}$ in ambient air.

(2) Single crystals of $\beta-\mathrm{Ga}_{2} \mathrm{O}_{3}$ were grown by the VB method without seeding in a full-diameter crucible and a conical crucible, and did not adhere to the walls of these platinum-rhodium alloy crucibles in either the vertical cylinder or conical configuration.

(3) We speculated that the $\beta-\mathrm{Ga}_{2} \mathrm{O}_{3}$ single crystal growth of the (100) faceted growth with the growth direction perpendicular to (100) plane without seeding was due to the remarkable growth rate anisotropy between the orientations perpendicular to (010) and (100) planes.

We concluded that $\beta-\mathrm{Ga}_{2} \mathrm{O}_{3}$ single crystals can be grown by the VB method using platinum-rhodium alloy crucibles in ambient air. Also, we plan future investigations on growing large-diameter single crystals by using seeds with various growth directions and on the control of their semiconductor characteristics by reducing residual impurities and doping with active impurities.

\section{References}

[1] H. H. Tippins, Optical Absorption and Photoconductivity in the Band Edge of $\beta$-Ga2O3, Phys. Rev. 140 [1A] (1965) A316-A319.

[2] M. Orita, H. Ohta, M. Hirano, and H. Hosono, Deep-ultraviolet transparent conductive $\beta-\mathrm{Ga}_{2} \mathrm{O}_{3}$ thin films, Appl. Phys. Lett. 77 [25] (2000) 4166-4168.

[3] M. Higashiwaki, K. Sasaki, A. Kuramata, T. Masui, and S. Yamakoshi, Gallium oxide $\left(\mathrm{Ga}_{2} \mathrm{O}_{3}\right)$ metal-semiconductor field-effect transistors on single-crystal $\beta-\mathrm{Ga}_{2} \mathrm{O}_{3}(010)$ substrates, Appl. Phys. Lett. 100 (2012) 013504.

[4] M. Higashiwaki, K. Sasaki, A. Kuramata, T. Masui, and S. Yamakoshi, Development of gallium oxide power devices, Phys. Status Solidi A 211[1] (2014) 21-26

[5] T. Oishi, Y. Koga, K. Harada, and M. Kasu, High-mobility $\beta-\mathrm{Ga}_{2} \mathrm{O}_{3}(\overline{2} 01)$ single crystals grown by edge-defined film-fed growth method and their Schottky barrier diodes with Ni contact, Appl. Phys. Express 8 (2015) 031101.

[6] Y. Tomm, P. Reiche, D. Klimm, and T. Fukuda, Czochralski grown $\mathrm{Ga}_{2} \mathrm{O}_{3}$ crystals, J. Cryst. Growth 220 (2000) 510-514

[7] E. G. Víllora, K. Shimamura, Y. Yoshikawa, T. Ujiie and K. Aoki, Electrical conductivity and carrier concentration control in $\beta-\mathrm{Ga}_{2} \mathrm{O}_{3}$ by Si doping, Appl. Phys. Lett. 92 (2008) 202120.

[8] Z. Galazka, R. Uecker, K. Irmscher, M. Albrecht, D. Klimm, M. Pietsch, M. Brützam, R. 
Bertram, S. Ganschow, and R. Fornari, Czochralski growth and characterization of $\beta-\mathrm{Ga}_{2} \mathrm{O}_{3}$ single crystals, Cryst. Res.Technol. 45 [12] (2010) 1229-1236.

[9] E. G. Víllora, S. Arjoca, K. Shimamura, D. Inomata, and K. Aoki, $\beta-\mathrm{Ga}_{2} \mathrm{O}_{3}$ and single-crystal phosphors for high-brightness white LEDs \& LDs, and $\beta-\mathrm{Ga}_{2} \mathrm{O}_{3}$ potential for next generation of power devices, Proc. of SPIE 8987 (2014) 89871U.

[10] N. Ueda, H. Hosono, R. Waseda, and H. Kawazoe, Synthesis and control of conductivity of ultraviolet transmitting $\beta-\mathrm{Ga}_{2} \mathrm{O}_{3}$ single crystals, Appl. Phys. Lett. 70 [26] (1997) 3561-3563.

[11] E. G. Víllora, K. Shimamura, Y. Yoshikawa, K. Aoki and N. Ichinose, Large-size $\beta-\mathrm{Ga}_{2} \mathrm{O}_{3}$ single crystals and wafers, J. Cryst. Growth 270 (2004) 420-426.

[12] Z. Galazka, K. Irmscher, R. Uecker, R. Bertram, M. Pietsch, A. Kwasniewski, M. Naumann, T. Schulz, R. Schewski, D. Klimm, and M. Bickermann, On the bulk $\beta-\mathrm{Ga}_{2} \mathrm{O}_{3}$ single crystals grown by the Czochralski method, J. Cryst. Growth 404 (2014) 184-191.

[13] H. Aida, K. Nishiguchi, H. Takeda, N. Aota, K. Sunakawa, and Y. Yaguchi, Growth of $\beta-\mathrm{Ga}_{2} \mathrm{O}_{3}$ Single Crystals by the Edge-Defined, Film Fed Growth Method, Jpn. J. Appl. Phys.47 [11] (2008) 8506-8509.

[14] E. G. Víllora, Y. Morioka, T. Atou, T. Sugawara, M. Kikuchi, and T. Fukuda, Infrared Reflectance and Electrical Conductivity of $\beta-\mathrm{Ga}_{2} \mathrm{O}_{3}$, Phys. Stat. Sol. (a) 193[1] (2002) 187-195.

[15] M. Zinkevich and F. Aldinger, Thermodynamic Assessment of the Gallium-Oxygen System, J. Am. Ceram. Soc. 87 [4] (2004) 683-691.

[16] D. Klimm, S. Ganschow, D. Schulz, R. Bertram, R. Uecker, P. Reiche, and R.Fornari, Growth of oxide compounds under dynamic atmosphere composition, J. Cryst. Growth 311 (2009) 534-536.

[17] S. Uda, H. Inaba, J. Harada, and K. Hoshikawa, Growth of langasite via Bridgman technique

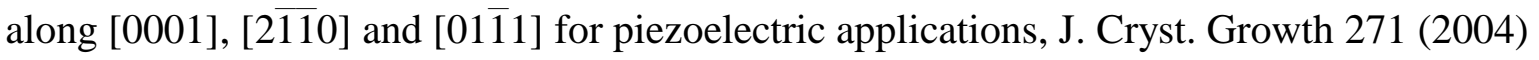
229-237.

[18] K. Hoshikawa, J. Osada, Y. Saitou, E. Ohba, C. Miyagawa, T. Kobayashi, J. Yanagisawa, M. Shinozuka, K. Kanno, Vertical Bridgman growth of sapphire -Seed crystal shapes and seeding characteristics, J. Cryst. Growth 395 (2014) 80-89.

[19] R. Roy, V. G. Hill, and E. F. Osborn, Polymorphism of $\mathrm{Ga}_{2} \mathrm{O}_{3}$ and the System $\mathrm{Ga}_{2} \mathrm{O}_{3}-\mathrm{H}_{2} \mathrm{O}$, J. Am. Chem. Soc. 74 [3] (1952) 719-22.

[20] H. Wartenberg and H. J. Reusch, Schmelzdiagramme höchstfeuerfester Oxyde. IV. (Aluminiumoxyd), Z. anorg. u. allg. Chem. 207 [1] (1932) 1-20.

[21] S. J. Schneider and J. L. Waring, Phase Equilibrium Relations in the $\mathrm{Sc}_{2} \mathrm{O}_{3}-\mathrm{Ga}_{2} \mathrm{O}_{3}$ System, J. Res. Nat. Bur. Stand. A 67A (1963) 19-25.

[22] Thermodynamic properties of individual substances, Edited by L. V. Gurvich, I. V. Veyts, and C. B. Alcock, CRC Press (Boca Raton, Ann Arbor, London, and Tokyo), Vol. 3 Part 1 (1981) pp.220.

[23] S. Celler, Crystal Structure of $\beta-\mathrm{Ga}_{2} \mathrm{O}_{3}$, J. Chem. Phys. 33 [3] (1960) 676-684. 
[24] G. KATZ and R. ROY, Flux Growth and Characterization of $\beta-\mathrm{Ga}_{2} \mathrm{O}_{3}$ Single Crystals, J. Am. Ceram. Soc., 49 [3] (1966) 168-169.

[25] K. Sasaki, A. Kuramata, T. Masui1, E. G. Víllora, K. Shimamura, and S.Yamakoshi, Device-Quality $\beta-\mathrm{Ga}_{2} \mathrm{O}_{3}$ Epitaxial Films Fabricated by Ozone Molecular Beam Epitaxy, Appl. Phys. Express 5 (2012) 035502. 
Fig. 1

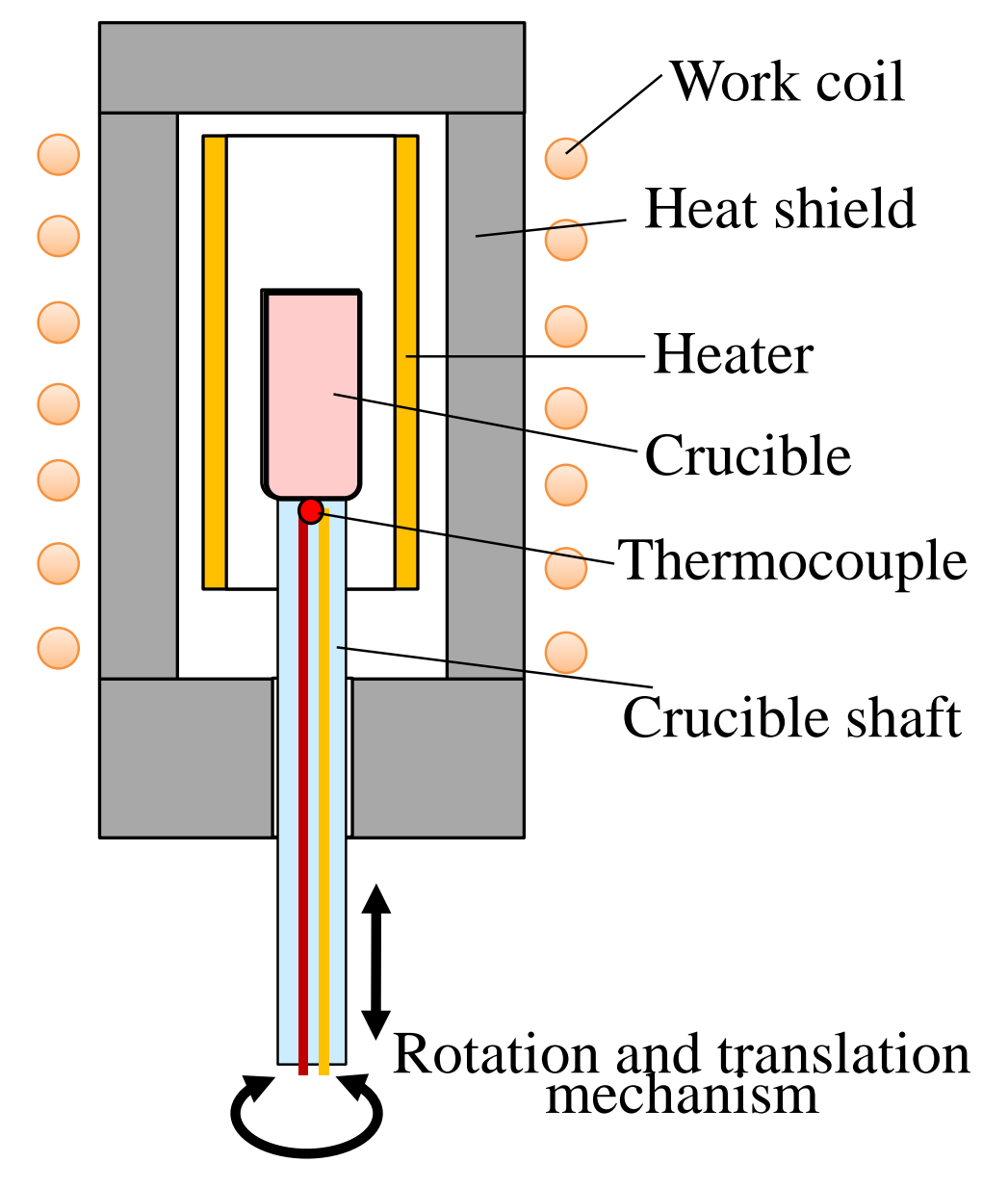

Fig. 1 Schematic diagram of the VB growth furnace used in the experiment. 
Fig. 2

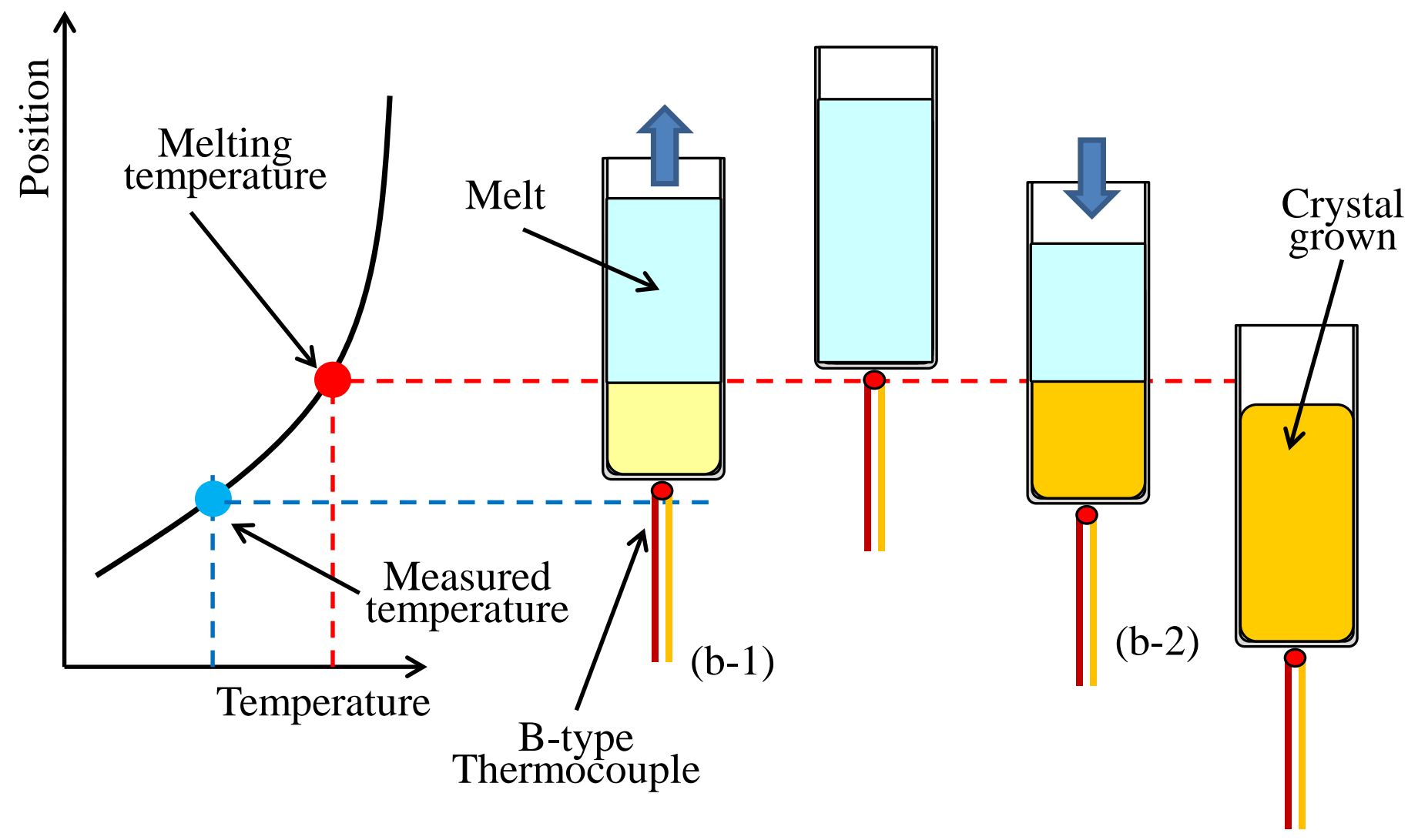

(a)

(b)

Fig. 2 Schematics of (a) the temperature distribution in the furnace and (b) the growth processes. 
Fig. 3

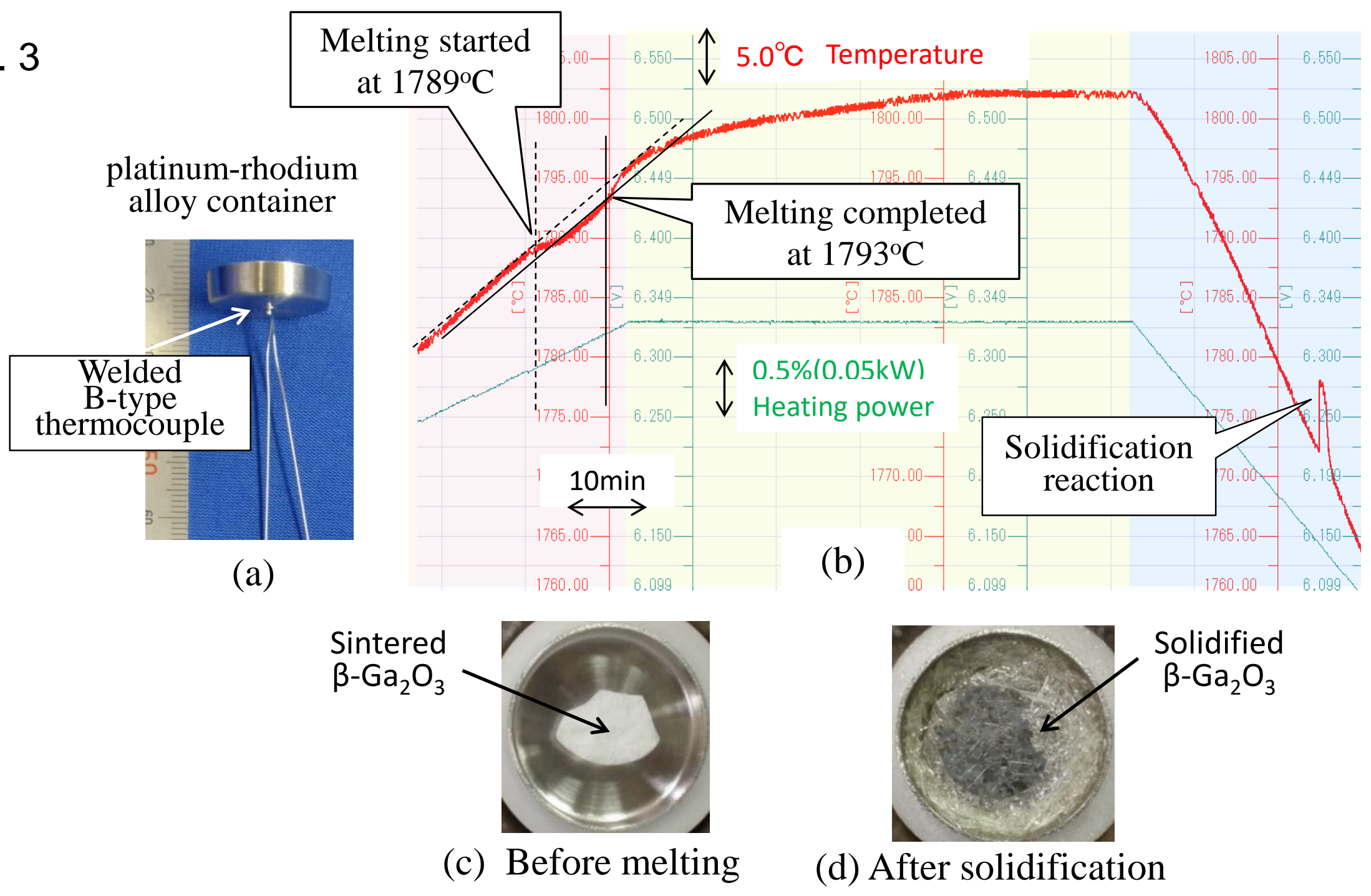

Fig. 3 Measuring the melting temperature of $\beta-\mathrm{Ga}_{2} \mathrm{O}_{3}$. 
Fig. 4

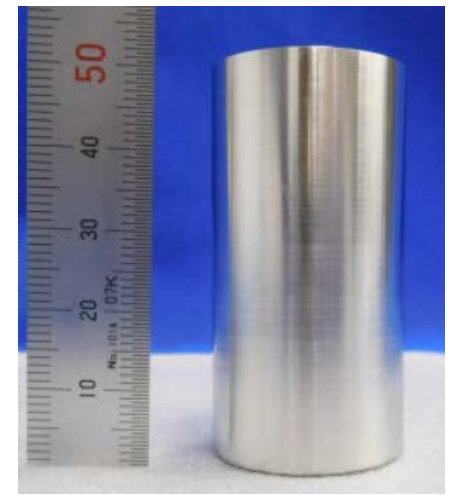

(a')

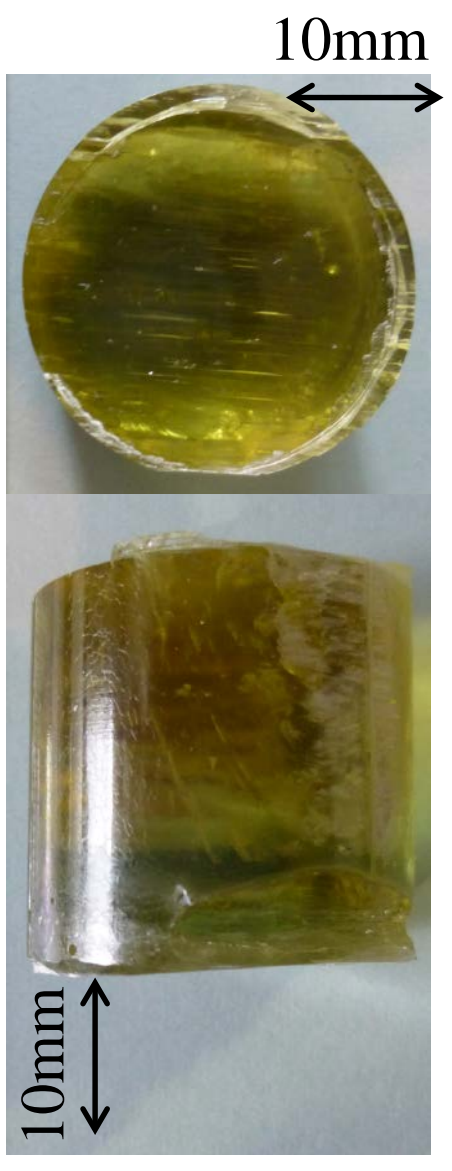

(a)

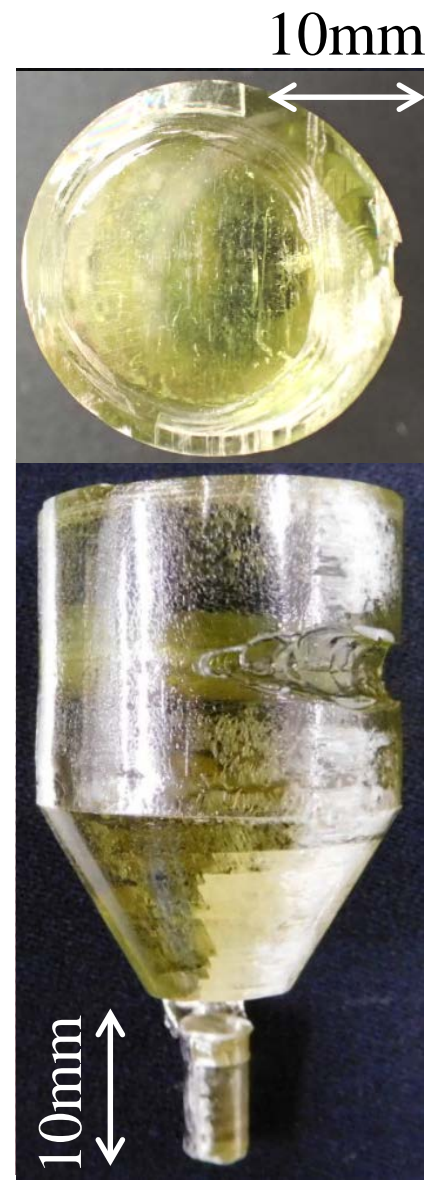

(b)

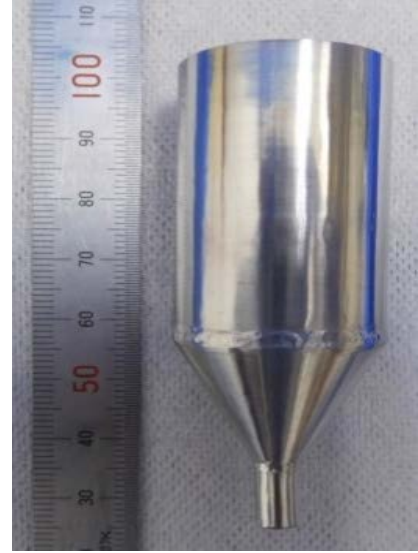

(b’)

Fig. $4 \beta-\mathrm{Ga}_{2} \mathrm{O}_{3}$ crystals grown by the VB method. (a) crystal grown in the full-diameter crucible (a'), and (b) crystal grown in the conical crucible (b'). 
Fig. 5

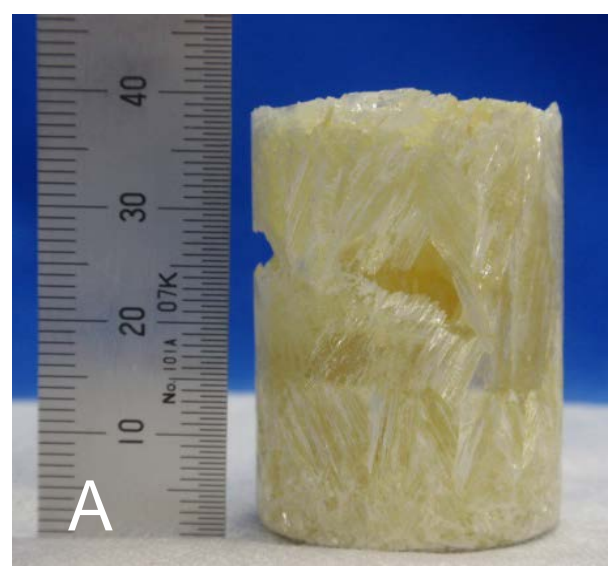

(a)

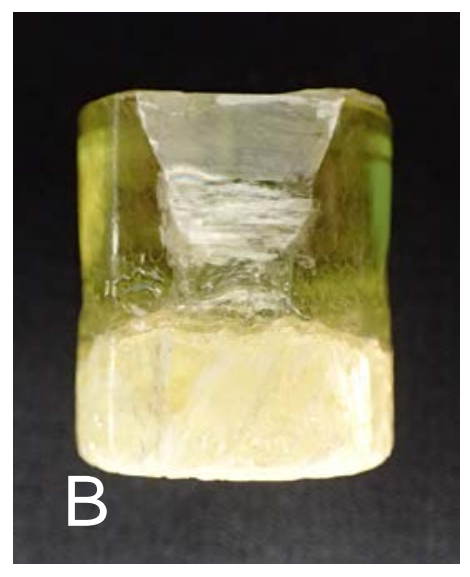

(b)

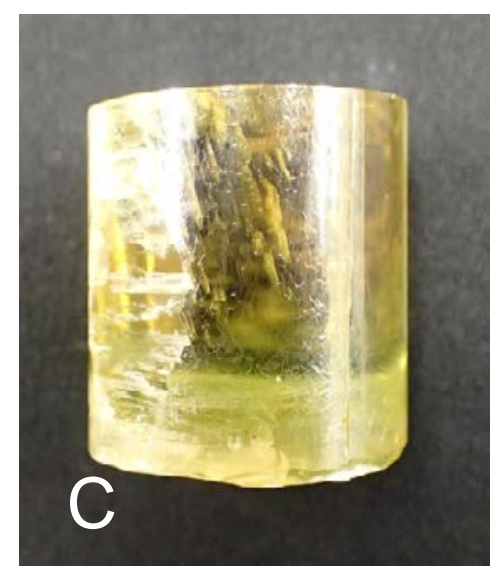

(c)

Fig. 5 Representative three crystals grown by VB method without seed. 
Fig. 6

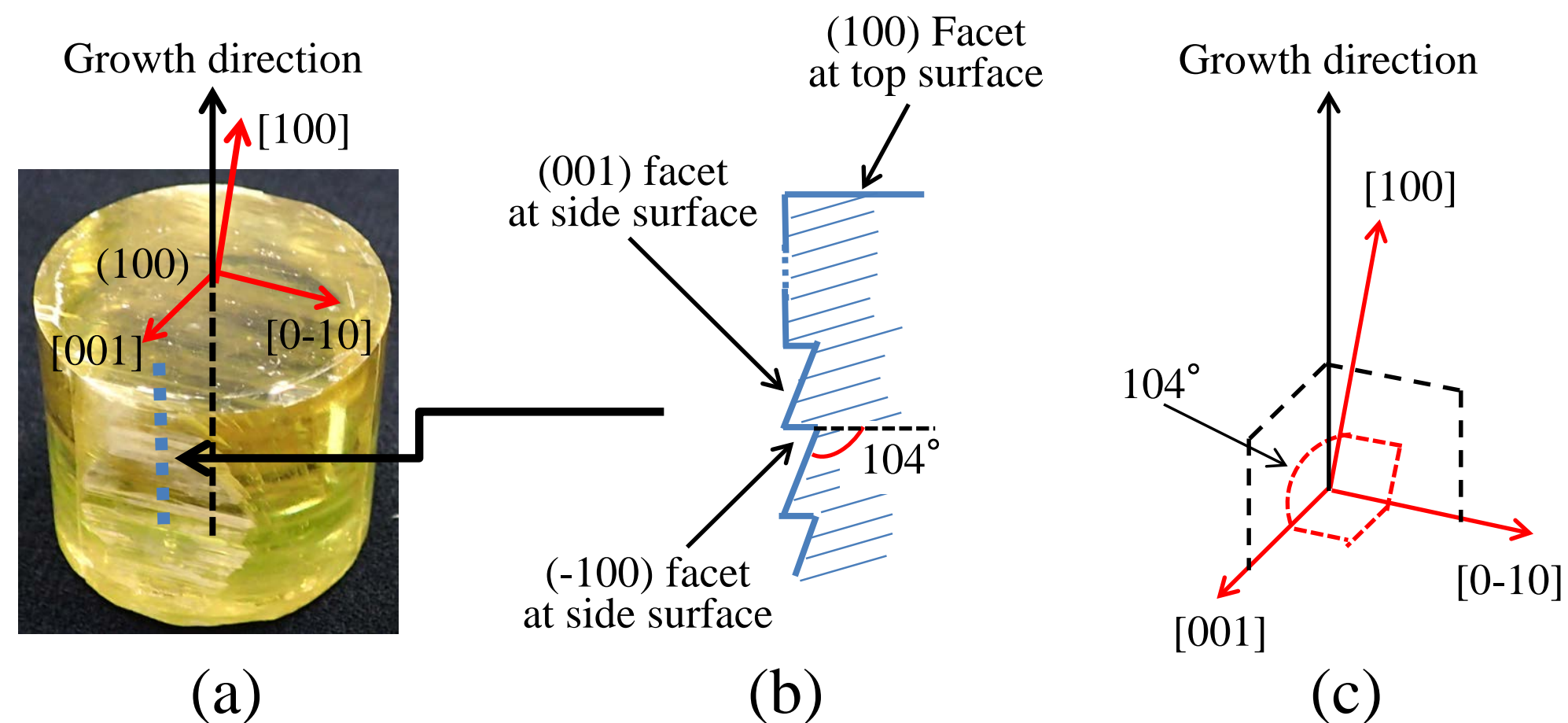

Fig. 6 Growth habit of a $\beta-\mathrm{Ga}_{2} \mathrm{O}_{3}$ single-crystal ingot spontaneously grown with a specific growth direction. 
Fig. 7

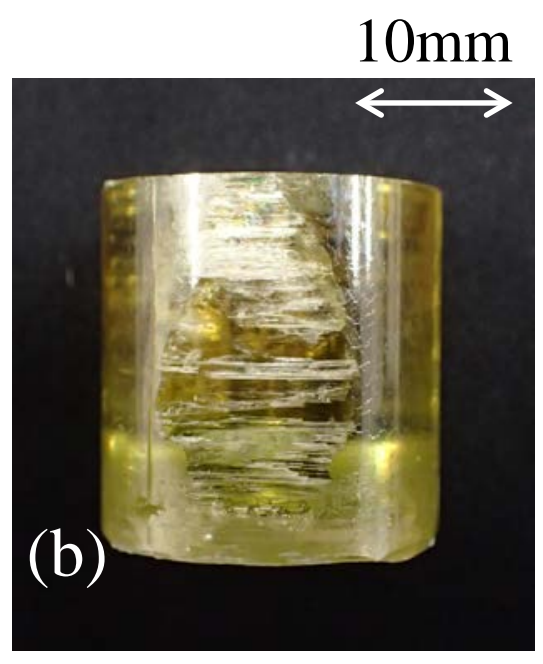

Growth direction

perpendicular to (100)

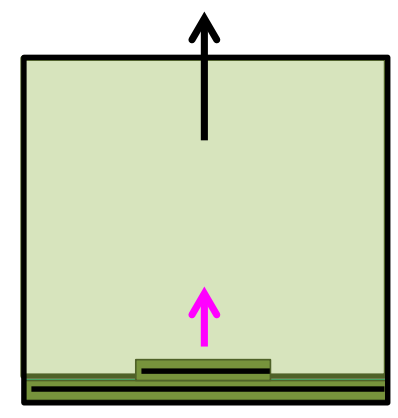

Lower

growth rate

$\uparrow$

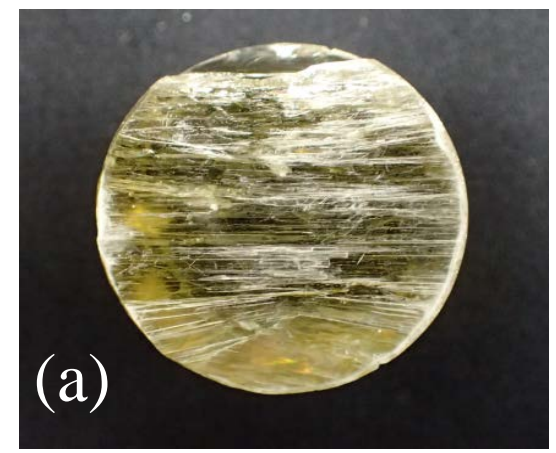

(b’)

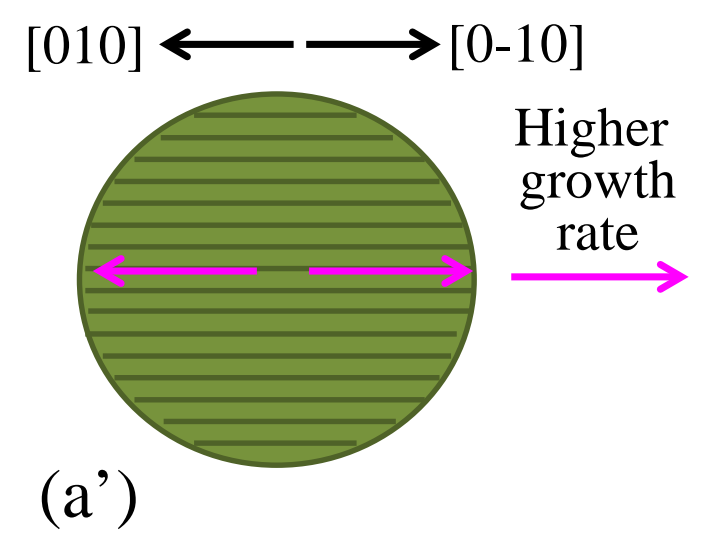

Fig. 7 Photographs of (a) bottom view, (b) side view, and schematics, of single crystal growth. 
Fig. 8

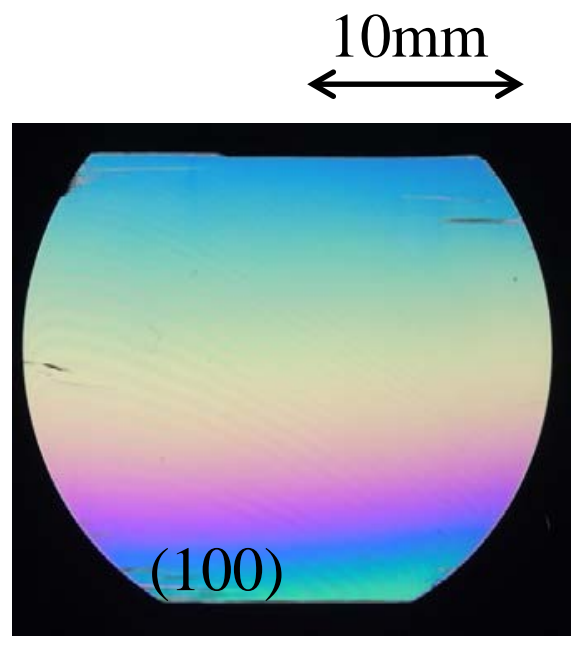

(a)

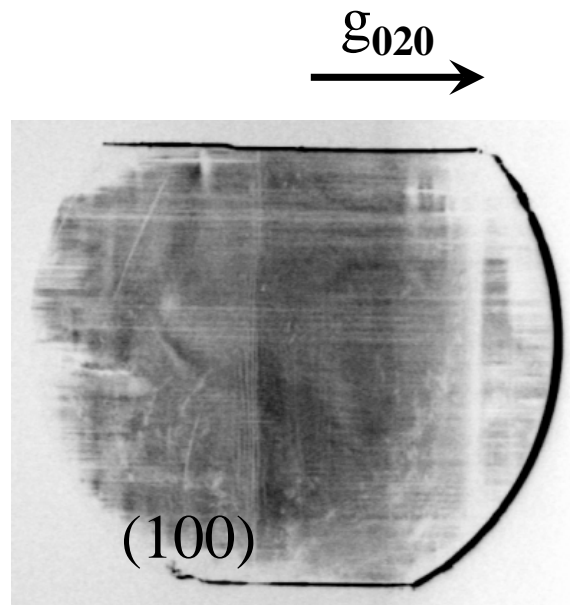

(b)

Fig. 8 (a) Crossed polarizer observation and (b) transmitted x-ray topographic images of a $\beta-\mathrm{Ga}_{2} \mathrm{O}_{3}(100)$ wafer. 
Table 1 Results of impurity analysis

\begin{tabular}{|c|c|}
\hline Element & $\begin{array}{c}\text { Result of analyze } \\
\text { [wt.ppm] }\end{array}$ \\
\hline $\mathrm{Na}$ & $0.1 \sim 1.0$ \\
\hline $\mathrm{Al}$ & $0.1 \sim 1.0$ \\
\hline $\mathrm{Si}$ & $1.0 \sim 10.0$ \\
\hline $\mathrm{Fe}$ & $0.1 \sim 1.0$ \\
\hline $\mathrm{Rh}$ & $3.0 \sim 30.0$ \\
\hline $\mathrm{Pt}$ & $0.5 \sim 5.0$ \\
\hline
\end{tabular}

